\title{
The Relationship Between Present-Centered Awareness and Attention, Burnout, and Compassion Fatigue in Oncology Health Professionals
}

\author{
Jamie Hegel ${ }^{1} \cdot$ Georgia K. B. Halkett ${ }^{2}$ (D) Penelope Schofield ${ }^{3,4}\left(\right.$ D $\cdot$ Clare S. Rees $^{1}$ (D) Brody Heritage $^{5}$ (D) \\ Sahil Suleman $^{6,7}$ (D) $\cdot$ Laura Inhestern $^{8}$ (D) Thomas Butler $^{9}$ (D) $\cdot$ Margaret I. Fitch ${ }^{10}$ (D) Lauren J. Breen $^{1}$ (i)
}

Accepted: 22 December 2020 / Published online: 5 January 2021

(C) The Author(s), under exclusive licence to Springer Science+Business Media, LLC part of Springer Nature 2021

\begin{abstract}
Objectives Oncology health professionals experience high levels of burnout and compassion fatigue, affecting their health and the care they provide. This study aimed to establish whether present-centered awareness and attention (a component of mindfulness) is uniquely associated with burnout and compassion fatigue in oncology professionals.

Methods An international sample of oncology professionals $(n=118)$ completed an online questionnaire with validated measures of present-centered awareness and attention, empathy, compassion fatigue, and burnout. Hierarchical multiple regressions were used to model relations among the independent variable (present-centered awareness and attention) and the criterion variables of burnout (disengagement, exhaustion) and compassion fatigue (compassion satisfaction, compassion burnout, secondary traumatic stress) after statistically controlling for empathy, age, gender, years of experience, and patient contact hours. Results Mean hours of patient contact per week was $23.52(\mathrm{SD}=13.62)$, with $26(22.03 \%)$ reporting $40 \mathrm{~h}$ or more. Higher hours of patient contact per week were positively associated with secondary traumatic stress. Present-centered awareness and attention was associated with lower disengagement, lower emotional exhaustion, higher compassion satisfaction, lower secondary traumatic stress, and lower compassion burnout. In each model, present-centered awareness accounted for unique variance after controlling for age, gender, years of experience, patient contact hours per week, and empathy scores. The amount of unique variance accounted for by present-centered awareness ranged from 4 to $10 \%$.

Conclusions Oncology professionals reporting higher levels of present-centered awareness and attention reported higher compassion satisfaction and lower secondary traumatic stress, compassion burnout, exhaustion, and disengagement. Promoting present-centered awareness may be a mechanism that contributes to less burnout in oncology professionals.
\end{abstract}

Keywords Oncology $\cdot$ Mindfulness $\cdot$ Present-centered awareness $\cdot$ Attention $\cdot$ Burnout $\cdot$ Compassion fatigue

A career as a health professional can be greatly rewarding, particularly for professionals who are compassionate, caring, and empathic (Wilkinson et al. 2017). Empathy involves both cognitive and affective processes and allows one to understand other's thoughts and emotions (Wagaman et al. 2015), but it may be a diminishable asset (Hunt et al. 2017).
Lauren J. Breen

Lauren.Breen@curtin.edu.au

1 School of Psychology, Curtin University, Perth, Western Australia, Australia

2 School of Nursing, Midwifery and Paramedicine, Curtin University, Perth, Western Australia, Australia

3 Department of Psychological Sciences, Swinburne University of Technology, Hawthorn, Victoria, Australia

4 Department of Behavioural Science, Peter MacCallum Cancer Centre, Melbourne, Victoria, Australia
5 School of Psychology and Exercise Science, Murdoch University, Perth, Western Australia, Australia

6 St George's University Hospitals NHS Foundation Trust, London, United Kingdom

7 University College London, London, United Kingdom

8 Department of Medical Psychology, University Medical Center Hamburg-Eppendorf, Hamburg, Germany

9 Mitchell Cancer Institute, University of South Alabama, Mobile, Alabama, United States of America

10 Bloomberg Faculty of Nursing, University of Toronto, Toronto, Canada 
Providing empathic support over long periods can have drawbacks for health professionals and their patients (Hunt et al. 2017). Patients report greater satisfaction with health care when they perceive empathy, but a lack of empathy can appear superficial and negatively affect the therapeutic relationship (Wilkinson et al. 2017). Significant emotional distress, such as anxiety and depression, can arise in health professionals who witness the pain and suffering of their patients, particularly those diagnosed with serious diseases, such as cancer (Najjar et al. 2009). Frequent exposure to such emotional disturbances can lead to an overall decrease in empathy, which may contribute to burnout and compassion fatigue (Gilmartin et al. 2017). Indeed, there is evidence for a negative relationship between empathy and burnout (Wilkinson et al. 2017).

Burnout has been theorized to have three componentsemotional exhaustion, depersonalization, and low personal accomplishment (Schaufeli et al. 2009) and is most commonly measured using the Maslach Burnout Inventory-General Survey (MBI-GS; Schaufeli et al. 1996). A systematic review of burnout in cancer care professionals showed that $8-51 \%$ suffer burnout and that the prevalence of emotional exhaustion, depersonalization, and low personal accomplishment in the cancer care providers (primarily physicians) was $36 \%$, $34 \%$, and $25 \%$, respectively (Trufelli et al. 2008). A more recent meta-analysis of burnout in oncologists showed the prevalence of emotional exhaustion, depersonalization, and low personal accomplishment to be $32 \%, 24 \%$, and $37 \%$, respectively (Yates and Samuel 2019).

Researchers have argued that the personal accomplishment component of the three-component approach has questionable validity and may best be considered a consequence of burnout rather than a component of burnout (Schaufeli et al. 2001). Furthermore, the MBI-GS has been criticized due to the items all being worded in the same direction. These issues led to the development of an alternative model of burnout involving two factors: work disengagement and exhaustion (Demerouti et al. 2003). In this approach, disengagement refers to distancing oneself from all aspects of work, not just disengaging from service recipients. Exhaustion refers to the consequence of ongoing exposure to job demands and includes both physical and cognitive aspects of exhaustion. The two-factor approach to burnout is measured using the Oldenburg Burnout Inventory (OLBI; Demerouti et al. 2003). Although originally developed in Germany, the English language version of the OLBI has been used extensively (Perron and Hiltz 2006; Scanlan and Still 2019; Shoji et al. 2015). A study of 277 Australian mental health workers (Scanlan and Still 2019) found high levels of burnout to be significantly associated with low job satisfaction and high turnover intention. The exhaustion component was significantly related to shift-work and the perceived emotional demands of the job. A longitudinal study conducted with 135 behavioral and mental health providers working with US military personnel found that levels of burnout (as measured by the OLBI) predicted secondary traumatic stress 6 months later (Shoji et al. 2015). The prevalence of burnout is reported to be $6.6-20.2 \%$ among psychosocial-oncology professionals, such as psychologists and counselors (Turnell et al. 2016). Although prevalence was not stated, burnout was reported to be higher among radiation oncologists than other oncology professionals (Jasperse et al. 2014).

The term compassion fatigue was first used to describe the phenomenon of emergency department nurses assuming the traumatic stress of their patients due to their empathic and caring nature (Johnson 1992). Compassion fatigue has three components-secondary traumatic stress which results from being deeply involved with a primarily traumatized patient (van Mol et al. 2015), compassion burnout, and low compassion satisfaction (Figley 1995). Studies show that approximately $25-26 \%$ of oncology and hospice nurses have a high risk of compassion fatigue (Abendroth and Flannery 2016; Duarte and Pinto-Gouveia 2017). Despite the similarities between burnout and compassion fatigue, they are distinct constructs. Burnout is the response to prolonged exposure to demanding interpersonal situations, whereas compassion fatigue is a specific response to working with traumatized patients (Figley 1995).

Although health professionals are becoming increasingly aware of the individual and workplace factors that may contribute to burnout and compassion fatigue (e.g., decreased levels of empathy and job resources, increased job demands; Cass et al. 2016; Cusack et al. 2016), there are few intervention studies aiming to prevent the development of burnout and compassion fatigue. One such intervention that has gained support is the self-care practice of mindfulness (Mills et al. 2018). Mindfulness is a way of being, whereby an individual adopts and maintains values of acceptance, openness, and patience while maintaining focus on any situation as it unfolds (Dobkin and Laliberte 2014). Mindfulness is considered to consist of two core components: present-centered awareness and non-judgmental acceptance (Bishop et al. 2004). Mindfulness practice cultivates greater awareness of the present moment and assists in developing more adaptive ways of responding to stress, and thus may improve symptoms of burnout and compassion fatigue in health professionals (Silver et al. 2018; Rees et al. 2018; Samios 2017; Slatyer et al. 2017).

A recent systematic review (Klein et al. 2020) explored the benefits of mindfulness-based interventions to reduce burnout in health professionals. The review included 34 quantitative studies; of these, only 9 were randomized controlled trials and only 4 showed significant improvement in burnout scores. The authors note that the majority of studies are methodologically weak (i.e., uncontrolled designs) and when the stronger studies are considered, results are inconsistent. The inconsistent findings for the effectiveness of mindfulness-based interventions in reducing burnout in health professionals warrant 
further investigation of the relationship between mindfulness and burnout in this population. Furthermore, as compassion fatigue is a negative workplace outcome that is uniquely associated with the work of those in helping professions, it is important that more is known about the relationship between mindfulness and compassion fatigue. Importantly, the role of mindfulness needs to be examined concurrently with other variables that are known to be associated with burnout and compassion fatigue. Advancing knowledge regarding the relationship between mindfulness and outcomes, such as burnout and compassion fatigue, will provide important information regarding the potential value of mindfulness as a treatment target or critical mechanism of change in any interventions aimed at reducing burnout and compassion fatigue.

There are numerous self-report scales used to measure mindfulness and each is based on different conceptualizations of the construct. The Mindful Attention Awareness Scale yields a single factor score capturing an individual's capacity to be present and conscious in daily life experiences. Studies have consistently reported a negative association between scores on this scale and psychological distress, including burnout (Jensen et al. 2016; Krasner et al. 2009; Xu et al. 2017). In this study, we aimed to investigate the relationship between present-centered awareness and the outcomes variables of burnout and compassion fatigue when considered alongside other important variables such as empathy. As previous research has found demographic variables to be associated with burnout in oncology professionals, these variables were controlled for in all analyses (Turnell et al. 2016). We hypothesized after controlling for participant individual differences (i.e., participant age, gender, experience in cancer care (years), and patient contact hours per week) and empathy, present-centered awareness and attention will account for a unique significant proportion of variance in the burnout components of disengagement and emotional exhaustion; and after controlling for participant individual differences (i.e., participant age, gender, experience in cancer care (years), and patient contact hours per week) and empathy, presentcentered awareness and attention will account for a unique significant proportion of variance in compassion satisfaction, compassion burnout, and secondary traumatic stress.

\section{Method}

\section{Participants}

Members of the Multinational Association of Supportive Care in Cancer (MASCC) online psycho-oncology forum (approximately 1100) received an email invitation to participate. MASCC members are health professionals working in cancer care, including but not limited to medical oncologists, surgical oncologists, radiation oncologists, nurses, social workers, dietitians, psychologists, radiation therapists, educators, and others interested in supportive care in cancer. Inclusion criteria were being professionals working within the field of cancer care, and an ability to read and complete a questionnaire in English. Health professionals were also invited to participate using Twitter.

Participants were 34 men $(28.8 \%)$ and 84 women $(71.2 \%)$, ranging from 22 to 68 years $(M=42.93$ years, $\mathrm{SD}=11.24)$. Participants were from 26 countries and 27 professions, most commonly medical oncologists $(n=21)$, nurses $(n=18)$, and radiation therapists $(n=16)$ from the USA $(n=24)$, Australia $(n=21)$, and the UK $(n=20)$. A substantial minority $(n=26$, $22.03 \%$ ) reported 40 or more hours of patient contact per week and $17(14.40 \%)$ reported having 25 or more years of experience.

\section{Procedure}

The MASCC Psychosocial Oncology Study Group approved the study in September 2018. Data collection occurred over a 3-week period in September 2018. MASCC emailed its members an invitation to participate in the study, which included a brief summary of the study and a link to the survey hosted on Qualtrics. Participants were invited to read a participant information sheet, which indicated participation was voluntary and their information would be anonymous. Participants then provided online informed consent prior to completing the measures. Estimated completion time of the questionnaire was approximately 10-20 min. Upon completion, participants were invited to provide an email address to receive a summary of the results and/or enter a prize draw to win one of five AUD\$20 amazon.com vouchers. A reminder invitation email was sent to all members on the MASCC list. Invitations to participate were also posted to the social media platform Twitter on two occasions to improve participation numbers.

\section{Measures}

Demographics The demographic data collected were age, gender, country of residence, profession, years of experience, and hours of direct patient contact per week.

Empathy Empathy was measured using the Basic Empathy Scale (BES; Jolliffe and Farrington 2006), a 20-item self-report measure of affective and cognitive empathy. Each item (e.g., "My friends' emotions don't affect me much") is rated on a 5 -point Likert scale ( $1=$ strongly disagree to $5=$ strongly agree), with an overall score range from 20 (empathy deficit) to 100 (high empathy) commonly reported (Litten et al. 2018). The BES displays adequate psychometric properties of construct, divergent, and convergent validity (Jolliffe and Farrington 2006) and internal and retest reliability (Carre et al. 2013). 
Compassion Fatigue The Professional Quality of Life Scale Version 5 (PROQOL5; Stamm 2010) is a 30-item self-report measure of levels of compassion satisfaction (e.g., "I get satisfaction from being able to help people"), compassion burnout (e.g., "I feel worn out because of my work as a health care provider"), and secondary traumatic stress ("I feel depressed because of the traumatic experiences of the people I help"). Each item is rated on a 5 -point Likert scale $(1=$ never to $5=$ very often) and scores range from 43 or less (low levels of compassion satisfaction, compassion burnout, and secondary traumatic stress), 44 to 56 (average levels of compassion satisfaction, compassion burnout, and secondary traumatic stress), and 57 or more (high levels of compassion satisfaction, compassion burnout, and secondary traumatic stress).

Burnout The Oldenburg Burnout Inventory (OLBI; Demerouti et al. 2003) is a 16-item self-report measure of work disengagement and exhaustion. The disengagement subscale has eight items and refers to distancing oneself from work as well as holding negative attitudes towards one's job. The exhaustion subscale also has eight items and refers to feelings of emptiness and physical, cognitive, and emotion exhaustion. Each item is rated on a 4-point Likert scale $(1=$ strongly agree to $4=$ strongly disagree), with higher scores indicating a higher level of burnout for each subscale (two items in the exhaustion subscale are reverse coded). Total scores for each subscale were generated by averaging all items, producing a possible score range of $1-4$. The OLBI displays adequate levels of convergent and construct validity, and is reported to have better psychometric properties than other burnout measures (Demerouti et al. 2003). Cutoff scores are $\geq 2.25$ for exhaustion and $\geq 2.1$ for disengagement (Peterson et al. 2008).

Present-Centered Awareness and Attention The 15-item Mindful Attention Awareness Scale (MAAS; Brown and Ryan 2003) was used to measure dispositional awareness and attention to the present experience. Each item is rated on a 6-point Likert scale $(1=$ almost always to $6=$ almost never $)$ with higher scores reflecting higher levels of dispositional awareness and attention. An example item is "I rush through activities without being really attentive to them." Scores were averaged across the 15 items, producing a possible score range of 1-4. The MAAS displays adequate concurrent and discriminant validity and reliability (Osman et al. 2015).

\section{Data Analyses}

Hierarchical linear multiple regression analyses, to detect the proportion of unique variance associated with presentcentered awareness for each model, were conducted. Cronbach's $\alpha$ reliability coefficients were calculated for each construct. As reliability estimation approaches such as calculating $\alpha$ are inflated by test length, the hierarchical omega $\left(\omega_{h}\right)$ coefficient was calculated to enhance the rigor of reliability checks prior to inferential analysis (see Revelle and Condon 2019 for further discussion on this topic). Analysis assumption checks (e.g., centering model predictors and verifying no multicollinearity concerns) were conducted before model interpretation. The hierarchical regression models included the following variables in the first block: participant age, gender, experience in cancer care (years), and patient contact hours per week. Participant empathy scores and participant presentcentered awareness were entered in blocks two and three respectively. Regression models were estimated using the package brms (Bürkner 2017) in $R$ software (R Core Team 2020), which employs a Bayesian estimation approach. Model fit of each model was verified prior to interpretation using the Leave-One-Out cross-validation approach integrated within brms (Bürkner 2017). Additionally, convergence of the models was verified from visual inspection of plots of the sampling chains overlapping with one another, and $\hat{R}$ coefficients of 1.00, prior to model interpretation (Kruschke 2015). Highest density interval estimates were calculated for an 95\% interval (McElreath 2018), with lower- and upper-bound estimate ranges that did not encompass a value of zero used to identify predictors that were related to the outcome variable of a respective model. Unstandardized and standardized model coefficients were estimated for each model. In total, five models were estimated for the outcome variables reflective of $\mathrm{H} 1$ and $\mathrm{H} 2$ : disengagement, exhaustion, compassion satisfaction, secondary traumatic stress, and burnout.

\section{Results}

A total of 216 participants commenced the online survey. Cases identified as having one or more incomplete measures were removed, resulting in a final sample of 118 cases. Pearson correlation coefficients, Cronbach's $\alpha$ reliability coefficients, hierarchical omega coefficients, and coefficients of central tendency for each variable in the forthcoming regression models are presented in Table 1. Examination of the items' saturation on the general latent factors presumed to underlie each measure appeared tenable for each measure, although an item each on the compassion burnout, secondary traumatic stress, and empathy measures suggested potential omission may marginally improve measure score reliability on each. Due to the contradictory information between the $\alpha$ and $\omega_{h}$ coefficients, the measures were scored per the measures' authors instructions (i.e., all items were included) to permit comparability across studies, although this point is returned to in the "Discussion" section. Therefore, we proceeded with estimation of the regression models. 
Table 1 Pearson correlation matrix and coefficients of central tendency for Modeled variables $(n=118)$

\begin{tabular}{|c|c|c|c|c|c|c|c|c|c|c|}
\hline & 1 & 2 & 3 & 4 & 5 & 6 & 7 & 8 & 9 & 10 \\
\hline \multicolumn{11}{|l|}{ 1. Age (years) } \\
\hline 2. Experience (years) & 0.72 & & & & & & & & & \\
\hline 3. Contact (hours) & -0.01 & -0.09 & & & & & & & & \\
\hline 4. P-C Awareness & 0.24 & 0.28 & 0.15 & $0.93(0.81)$ & & & & & & \\
\hline 5. Disengagement & -0.30 & -0.35 & -0.07 & -0.42 & $0.84(0.69)$ & & & & & \\
\hline 6. Exhaustion & -0.28 & -0.27 & -0.01 & -0.35 & 0.76 & $0.86(0.79)$ & & & & \\
\hline $\begin{array}{l}\text { 7. Compassion } \\
\text { Satisfaction }\end{array}$ & 0.19 & 0.21 & 0.00 & 0.32 & -0.63 & -0.49 & $0.89(0.81)$ & & & \\
\hline $\begin{array}{l}\text { 8. Compassion } \\
\text { Burnout }\end{array}$ & -0.33 & -0.34 & 0.13 & -0.39 & 0.67 & 0.67 & -0.72 & $0.81(0.58)$ & & \\
\hline 9. Secondary TS & -0.25 & -0.30 & 0.25 & -0.25 & 0.34 & 0.38 & -0.33 & 0.55 & $0.76(0.63)$ & \\
\hline 10. Empathy & -0.13 & -0.01 & 0.01 & 0.03 & 0.00 & 0.19 & 0.21 & -0.02 & 0.03 & $0.86(0.68)$ \\
\hline$M$ & 42.93 & 12.35 & 23.52 & 3.78 & 2.24 & 2.55 & 39.39 & 24.38 & 23.21 & 75.46 \\
\hline$S D$ & 11.24 & 7.85 & 13.62 & 0.92 & 0.54 & 0.53 & 6.26 & 6.21 & 5.28 & 8.91 \\
\hline
\end{tabular}

For variables other than age, experience (years), and contact (hours), Cronbach's $\alpha$ ( $\left.\omega_{\text {Hierarchical }}\right)$ are represented along the diagonal of the table Experience experience in cancer care, Contact patient contact hours per week, $P$ - $C$ present-centered, $T S$ traumatic stress

\section{Burnout: Disengagement and Emotional Exhaustion}

Table 2 displays the results for the two hierarchical multiple regressions for disengagement and emotional exhaustion. Approximately $16 \%$ of the variance in disengagement was associated with participants' individual difference variables within the first block, with participants' years of experience in cancer care (i.e., more experience was associated with lessened reported disengagement) accounting for unique variance. Adding participant empathy scores in the second block did not account for notable variance in disengagement $(\sim \Delta 1 \%)$; however, the inclusion of present-centered awareness in the third block accounted for approximately $9 \%$ additional variance in disengagement scores. The negative coefficient for present-centered awareness suggested that as participants' reported scores increased, disengagement scores decreased. With present-centered awareness added in the third block of predictors, years of experience in cancer care no longer accounted for unique variance in the model.

For emotional exhaustion, the individual difference variables entered in the first block of predictors jointly accounted for approximately $11 \%$ of the outcome's variance. When empathy was included in the second block, empathy accounted for an additional $3 \%$ of variance in emotional exhaustion. However, the coefficient estimate's $95 \%$ highest density interval encompassed a value of zero; therefore, clear evidence of empathy's accounting of unique variance in exhaustion was not found at this stage of analysis. When present-centered awareness was entered in the third block, this variable accounted for approximately $8 \%$ additional variance in emotional exhaustion, and its negative coefficient direction suggested that greater present-centered awareness was associated with lower emotional exhaustion.

\section{Compassion Fatigue: Compassion Satisfaction, Compassion Burnout, and Secondary Traumatic Stress}

Table 3 displays the results for the three hierarchical multiple regressions for the caring profession quality of life subscales. The individual differences variables entered in block one of the regression model accounted for approximately $9 \%$ of variance in compassion satisfaction. When empathy scores were entered in the second block of the regression model, accounting for approximately $4 \%$ additional unique variance in compassion satisfaction, higher empathy scores were associated with higher compassion satisfaction scores. When presentcentered awareness was entered in the third block of the regression model (explaining an additional $7 \%$ of the variance in compassion satisfaction scores), both empathy and presentcentered awareness were positively related to higher compassion satisfaction scores, accounting for non-marginal unique variance.

When estimating secondary traumatic stress scores, individual differences variables entered in the first block of the model collectively explained $16 \%$ of the variance in this outcome. Higher numbers of hours of patient contact per week were associated with higher secondary traumatic stress scores. The inclusion of empathy in the second block of predictors explained a marginal $1 \%$ additional variance in secondary traumatic stress scores. However, present-centered awareness explained approximately $4 \%$ unique variance in secondary traumatic stress, where participants with higher presentcentered awareness scores had on average lower secondary traumatic stress scores.

Compassion burnout scores had $16 \%$ of their variance explained by the individual differences variables entered in block one according to the final regression model examined. 
Table 2 Regression models explaining disengagement and exhaustion outcome variables $(n=118)$

\begin{tabular}{|c|c|c|c|c|c|c|}
\hline \multirow[b]{2}{*}{ Variables } & \multicolumn{3}{|c|}{ Disengagement } & \multicolumn{3}{|l|}{ Exhaustion } \\
\hline & $B(\mathrm{SE})$ & $95 \% \mathrm{HDI}$ & $\beta(\mathrm{SE})$ & $B(\mathrm{SE})$ & $95 \% \mathrm{HDI}$ & $\beta(\mathrm{SE})$ \\
\hline \multicolumn{7}{|l|}{ Model 1} \\
\hline Intercept & $0.08(0.09)$ & $(-0.10,0.25)$ & $0.14(0.17)$ & $-0.05(0.09)$ & $(-0.23,0.12)$ & $-0.10(0.17)$ \\
\hline Age (years) & $-0.01(0.01)$ & $(-0.02,0.01)$ & $-0.11(0.013)$ & $-0.01(0.01)$ & $(-0.02,0.00)$ & $-0.15(0.13)$ \\
\hline Gender (female) & $-0.11(0.11)$ & $(-0.32,0.10)$ & $-0.19(0.20)$ & $0.08(0.11)$ & $(-0.14,0.29)$ & $0.14(0.20)$ \\
\hline Experience (years) & $-0.02(0.01)$ & $(-0.04,-0.00)$ & $-0.27(0.13)$ & $-0.01(0.01)$ & $(-0.03,0.01)$ & $-0.17(0.13)$ \\
\hline Contact (hours) & $-0.00(0.00)$ & $(-0.01,0.00)$ & $-0.10(0.09)$ & $-0.00(0.00)$ & $(-0.01,0.01)$ & $-0.03(0.09)$ \\
\hline$\Delta R^{2}$ & 0.16 & & & 0.11 & & \\
\hline \multicolumn{7}{|l|}{ Model 2} \\
\hline Intercept & $0.08(0.09)$ & $(-0.11,0.26)$ & $0.14(0.17)$ & $-0.02(0.09)$ & $(-0.20,0.16)$ & $-0.03(0.17)$ \\
\hline Age (years) & $-0.01(0.01)$ & $(-0.02,0.01)$ & $-0.11(0.13)$ & $-0.01(0.01)$ & $(-0.02,0.01)$ & $-0.12(0.13)$ \\
\hline Gender (female) & $-0.11(0.11)$ & $(-0.33,0.011)$ & $-0.20(0.21)$ & $0.02(0.11)$ & $(-0.19,0.24)$ & $0.04(0.21)$ \\
\hline Experience (years) & $-0.02(0.01)$ & $(-0.04,-0.00)$ & $-0.28(0.13)$ & $-0.01(0.01)$ & $(-0.03,0.00)$ & $-0.18(0.13)$ \\
\hline Contact (hours) & $-0.00(0.00)$ & $(-0.01,0.00)$ & $-0.10(0.09)$ & $-0.00(0.00)$ & $(-0.01,0.01)$ & $-0.03(0.09)$ \\
\hline Empathy & $0.00(0.01)$ & $(-0.01,0.01)$ & $0.01(0.09)$ & $0.01(0.01)$ & $(-0.00,0.02)$ & $0.16(0.10)$ \\
\hline$\Delta R^{2}$ & 0.01 & & & 0.03 & & \\
\hline \multicolumn{7}{|l|}{ Model 3} \\
\hline Intercept & $0.09(0.09)$ & $(-0.09,0.26)$ & $0.15(0.16)$ & $-0.01(0.09)$ & $(-0.19,0.16)$ & $-0.02(0.17)$ \\
\hline Age (years) & $-0.00(0.01)$ & $(-0.02,0.01)$ & $-0.09(0.12)$ & $-0.00(0.01)$ & $(-0.02,0.01)$ & $-0.10(0.13)$ \\
\hline Gender (female) & $-0.12(0.11)$ & $(-0.33,0.09)$ & $-0.22(0.19)$ & $0.01(0.11)$ & $(-0.19,0.22)$ & $0.03(0.20)$ \\
\hline Experience (years) & $-0.01(0.01)$ & $(-0.03,0.00)$ & $-0.19(0.12)$ & $-0.01(0.01)$ & $(-0.02,0.01)$ & $-0.11(0.13)$ \\
\hline Contact (hours) & $-0.00(0.00)$ & $(-0.01,0.00)$ & $-0.05(0.09)$ & $0.00(0.00)$ & $(-0.01,0.01)$ & $0.02(0.09)$ \\
\hline Empathy & $0.00(0.01)$ & $(-0.01,0.01)$ & $0.02(0.09)$ & $0.01(0.01)$ & $(-0.00,0.02)$ & $0.18(0.09)$ \\
\hline P-C Awareness & $-0.01(0.00)$ & $(-0.02,-0.01)$ & $-0.34(0.09)$ & $-0.01(0.00)$ & $(-0.02,-0.00)$ & $-0.31(0.09)$ \\
\hline$\Delta R^{2}$ & 0.09 & & & 0.08 & & \\
\hline
\end{tabular}

Experience experience in cancer care, Contact patient contact hours per week, $P$ - $C$ present-centered, $T S$ traumatic stress

In a similar pattern of findings to the secondary traumatic stress model, the inclusion of empathy in the second block of the regression model explained a marginal $1 \%$ additional variance in compassion burnout scores. The inclusion of present-centered awareness in the third predictor block explained an additional $10 \%$ unique variance in compassion burnout scores, which suggested that participants with higher scores on present-centered awareness reported lower compassion burnout scores.

\section{Discussion}

In this study, we aimed to determine the role of a specific type of mindfulness, namely present-centered awareness and attention, by examining its relationship to burnout and compassion fatigue among oncology health professionals after controlling for participants' age, gender experience, contact hours with patients, and reported empathy scores. Inspection of the mean scores for the sample revealed that they were above the cutoff scores for both the burnout subscales of disengagement and exhaustion. Despite this, their scores on the compassion burnout and secondary traumatic stress were in the low range. This is not necessarily surprising given that compassion fatigue (compassion burnout and secondary traumatic stress) is distinct from burnout (Figley 1995), and there is evidence that it may be a precursor to the development of secondary traumatic stress. For example, a longitudinal study by Shoji et al. (2015) found that burnout preceded the development of secondary traumatic stress in a sample of 135 behavioral and mental health providers working with US military personnel. These findings suggest that, despite elevated levels of exhaustion and disengagement, these health professionals were still scoring highly on empathy and compassion satisfaction and not experiencing compassion fatigue.

We found evidence that present-centered awareness is significantly associated with burnout and compassion fatigue in oncology professionals and as such may be important to target in interventions aiming to reduce burnout. Present-centered awareness and attention accounted for unique variance in all 
Table 3 Regression models explaining professional quality of life caring outcome variables $(n=118)$

\begin{tabular}{|c|c|c|c|c|c|c|c|c|c|}
\hline \multirow[b]{2}{*}{ Variables } & \multicolumn{3}{|c|}{ Compassion satisfaction } & \multicolumn{3}{|c|}{ Secondary traumatic stress } & \multicolumn{3}{|l|}{ Burnout } \\
\hline & $B(\mathrm{SE})$ & $95 \% \mathrm{HDI}$ & $\beta(\mathrm{SE})$ & $B(\mathrm{SE})$ & $95 \% \mathrm{HDI}$ & $\beta(\mathrm{SE})$ & $B(\mathrm{SE})$ & $95 \% \mathrm{HDI}$ & $\beta(\mathrm{SE})$ \\
\hline \multicolumn{10}{|l|}{ Model 1} \\
\hline Intercept & $-1.45(1.09)$ & $(-3.61,0.69)$ & $-0.23(0.17)$ & $0.20(0.88)$ & $(-1.50,1.96)$ & $0.04(0.17)$ & $0.39(1.02)$ & $(-1.60,2.40)$ & $0.06(0.17)$ \\
\hline Age (years) & $0.06(0.07)$ & $(-0.08,0.21)$ & $0.11(0.13)$ & $-0.04(0.06)$ & $(-0.16,0.07)$ & $-0.09(0.13)$ & $-0.11(0.07)$ & $(-0.25,0.03)$ & $-0.20(0.13)$ \\
\hline Gender (female) & $2.05(1.31)$ & $(-0.53,4.62)$ & $0.33(0.21)$ & $-0.28(1.05)$ & $(-2.36,1.74)$ & $-0.05(0.20)$ & $-0.55(1.22)$ & $(-2.94,1.83)$ & $-0.09(0.20)$ \\
\hline Experience (years) & $0.09(0.11)$ & $(-0.12,0.30)$ & $0.11(0.13)$ & $-0.14(0.09)$ & $(-0.31,0.03)$ & $-0.21(0.13)$ & $-0.15(0.10)$ & $(-0.35,0.05)$ & $-0.19(0.13)$ \\
\hline Contact (hours) & $0.01(0.04)$ & $(-0.07,0.10)$ & $0.03(0.09)$ & $0.09(0.03)$ & $(0.02,0.15)$ & $0.22(0.09)$ & $0.05(0.04)$ & $(-0.03,0.12)$ & $0.10(0.09)$ \\
\hline$\Delta R^{2}$ & 0.09 & & & 0.16 & & & 0.16 & & \\
\hline \multicolumn{10}{|l|}{ Model 2} \\
\hline Intercept & $-0.92(1.09)$ & $(-3.07,1.25)$ & $-0.15(0.18)$ & $0.23(0.90)$ & $(-1.56,2.00)$ & $0.04(0.17)$ & $0.29(1.07)$ & $(-1.82,2.40)$ & $0.05(0.17)$ \\
\hline Age (years) & $0.09(0.07)$ & $(-0.06,0.23)$ & $0.15(0.13)$ & $-0.04(0.06)$ & $(-0.16,0.08)$ & $-0.09(0.13)$ & $-0.11(0.07)$ & $(-0.25,0.03)$ & $-0.21(0.13)$ \\
\hline Gender (female) & $1.30(1.31)$ & $(-1.29,3.89)$ & $0.20(0.21)$ & $-0.34(1.09)$ & $(-2.42,1.84)$ & $-0.06(0.21)$ & $-0.41(1.29)$ & $(-2.92,2.14)$ & $-0.07(0.21)$ \\
\hline Experience (years) & $0.07(0.10)$ & $(-0.13,0.28)$ & $0.09(0.13)$ & $-0.14(0.09)$ & $(-0.32,0.03)$ & $-0.21(0.13)$ & $-0.14(0.10)$ & $(-0.34,0.06)$ & $-0.18(0.13)$ \\
\hline Contact (hours) & $0.01(0.04)$ & $(-0.07,0.09)$ & $0.02(0.09)$ & $0.09(0.03)$ & $(0.02,0.15)$ & $0.22(0.09)$ & $0.05(0.04)$ & $(-0.03,0.13)$ & $0.10(0.09)$ \\
\hline Empathy & $0.14(0.07)$ & $(0.01,0.28)$ & $0.21(0.10)$ & $0.01(0.06)$ & $(-0.10,0.12)$ & $0.02(0.09)$ & $-0.03(0.06)$ & $(-0.16,0.10)$ & $-0.04(0.09)$ \\
\hline$\Delta R^{2}$ & 0.04 & & & 0.01 & & & 0.01 & & \\
\hline \multicolumn{10}{|l|}{ Model 3} \\
\hline Intercept & $-0.99(1.07)$ & $(-3.06,1.12)$ & $-0.16(0.17)$ & $0.28(0.88)$ & $(-1.43,2.03)$ & $0.06(0.17)$ & $0.37(1.00)$ & $(-1.61,2.35)$ & $0.06(0.16)$ \\
\hline Age (years) & $0.08(0.07)$ & $(-0.07,0.22)$ & $0.14(0.13)$ & $-0.04(0.06)$ & $(-0.15,0.08)$ & $-0.08(0.13)$ & $-0.10(0.07)$ & $(-0.23,0.03)$ & $-0.18(0.12)$ \\
\hline Gender (female) & $1.40(1.28)$ & $(-1.09,3.89)$ & $0.22(0.21)$ & $-0.40(1.06)$ & $(-2.49,1.67)$ & $-0.08(0.20)$ & $-0.53(1.20)$ & $(-2.87,1.83)$ & $-0.09(0.20)$ \\
\hline Experience (years) & $0.02(0.11)$ & $(-0.19,0.22)$ & $0.02(0.13)$ & $-0.10(0.09)$ & $(-0.27,0.07)$ & $-0.15(0.13)$ & $-0.08(0.10)$ & $(-0.27,0.12)$ & $-0.09(0.12)$ \\
\hline Contact (hours) & $-0.01(0.04)$ & $(-0.09,0.07)$ & $-0.03(0.09)$ & $0.10(0.03)$ & $(0.03,0.17)$ & $0.26(0.09)$ & $0.07(0.04)$ & $(-0.00,0.15)$ & $0.16(0.09)$ \\
\hline Empathy & $0.14(0.06)$ & $(0.01,0.26)$ & $0.19(0.09)$ & $0.02(0.05)$ & $(-0.09,0.12)$ & $0.03(0.09)$ & $-0.02(0.06)$ & $(-0.14,0.10)$ & $-0.03(0.09)$ \\
\hline P-C Awareness & $0.12(0.04)$ & $(0.04,0.21)$ & $0.28(0.09)$ & $-0.09(0.03)$ & $(-0.16,-0.02)$ & $-0.23(0.09)$ & $-0.15(0.04)$ & $(-0.23,-0.08)$ & $-0.34(0.09)$ \\
\hline$\Delta R^{2}$ & 0.07 & & & 0.04 & & & 0.10 & & \\
\hline
\end{tabular}

of the models tested (i.e., after controlling for shared variance associated with the competing predictors of age, gender). This result is consistent with previous research showing that mindfulness is associated with all components of burnout (Taylor and Millear 2016). Present-centered awareness had its biggest unique contribution to disengagement, emotional exhaustion, and compassion burnout on the basis of the unique variance $\left(\Delta R^{2}\right)$ associated with the introduction of present-centered awareness in the models of these outcome variables. When examining the burnout subscales of disengagement and emotional exhaustion, after controlling for empathy, presentcentered awareness was negatively associated with disengagement and emotional exhaustion. In explaining professional quality of life, after controlling for empathy and individual differences, present-centered awareness had a positive association with compassion satisfaction and a negative association with secondary traumatic stress and burnout. These findings are consistent with previous studies showing that presentcentered awareness is reliably associated with burnout scores (Krasner et al. 2009; Xu et al. 2017).

Empathy was not related to disengagement or emotional exhaustion in this sample. This finding is in contrast to the negative relationship (Wilkinson et al. 2017) and positive relationship (Kellner 2001) in previous studies between empathy and burnout in a sample of emergency health professionals. Furthermore, empathy explained compassion satisfaction scores, but not secondary traumatic stress or compassion burnout scores. This suggests that empathy is an important part of gaining satisfaction from the work of helping others, which is in line with an earlier study that also found empathic concern to be associated with compassion satisfaction (Duarte and Pinto-Gouveia 2017).

Our sample had lower levels of present-centered awareness and attention, but similar compassion satisfaction scores, to a study of mental health workers (Samios 2017). Interestingly, a large proportion of the sample had $40 \mathrm{~h}$ or more of patient contact per week. Increased workload has been identified as being associated with greater burnout (Jasperse et al. 2014), which was consistent with our findings that higher contact hours was associated with higher compassion burnout.

\section{Limitations and Future Research}

One issue affecting the interpretation of the burnout scores is that the recommended cutoff scores used for the OLBI are based on a different measure of burnout (MBI) and a nonEnglish speaking sample. Despite this limitation, we note that the mean scores obtained in our study are very close to those obtained with other samples of health professionals who completed the English language version of the OLBI. For example, Scanlan and Still (2019) found a mean of 2.38 on exhaustion and 2.24 on disengagement in a sample of Australian mental health workers. Similarly, Perron and Hiltz (2006) found a mean of 2.26 on exhaustion and 2.21 
on disengagement in a sample of forensic interviewers in the USA. These figures closely correspond with the means found in our sample (exhaustion $=2.55$, disengagement $=2.24$ ).

The use of the MAAS means that the study focuses on a component of mindfulness (i.e., present-centered awareness and attention), rather than the full mindfulness construct (Baer et al. 2006). A disadvantage of the unidimensional MAAS is that it only allows investigation of mechanisms involving a very specific aspect of mindfulness, namely acting with awareness (Coffey and Hartman 2008), therefore omitting a comprehensive examination of mindfulness and key mechanisms. Furthermore, all items of the MAAS are worded negatively or describe the absence of attentional focus, meaning that it might measure perceived inattention as opposed to attention (Van Dam et al. 2010).

Our reliance on self-reported measures means that common method bias is another limitation. Participant self-report ratings of multiple constructs in the same survey can inflate correlations among the items measuring these constructs (Podsakoff et al. 2003). The potential for correlation attenuation due to reliability was noted for the compassion burnout, secondary traumatic stress, and empathy measures used in this study, although item removal as described in the "Results" section only led to marginal improvements in score reliability. Future research may wish to use alternative measures that map to these constructs.

We used a nonprobability convenience sample belonging to a dedicated cancer care online forum, which yielded a heterogeneous international sample. However, this diversity precluded analyses within each discipline and country and the participation rate was low. We were unable to ascertain the response rate because we used convenience sampling from MASCC and Twitter. Additionally, although the sample was experienced and worked long hours, and therefore ideal candidates for this study, the findings might not be generalizable to all oncology health professionals. Likewise, the sample was also predominately female, although this is not dissimilar to other studies in nursing (Hegney et al. 2014) and oncology (Jasperse et al. 2014).

The cross-sectional design is a critical shortcoming because it cannot determine whether present-centered awareness increases compassion satisfaction and reduces burnout and secondary traumatic stress. A longitudinal study could determine the directionality of these relationships and future studies using the MBI (Maslach and Jackson 1981) would facilitate comparisons with the majority of research on burnout (Yates and Samuel 2019). Similarly, while this study provides important information as to the relationship between presentcentered awareness and burnout, future studies measuring other components of mindfulness (i.e., acceptance) are needed to strengthen conclusions as to the overall importance of mindfulness constructs in explaining burnout in this professional group.
Acknowledgments We thank the Multinational Association of Supportive Care in Cancer for assisting with participant recruitment.

Authors' Contributions JH, GH, and LB designed the study. JH wrote the first version of the manuscript. LB and CR substantially rewrote the manuscript. $\mathrm{BH}$ analyzed the data and wrote the results. GH, PS, SS, LI, TB, MF, and LB assisted with sample recruitment. LB oversaw the execution of the study and the writing and editing and the manuscript. All authors approved the final version of the manuscript for submission.

\section{Compliance with Ethical Standards}

Conflict of Interest The authors declare they have no conflicts of interest.

Ethical Approval All procedures performed in studies involving human participants were in accordance with the ethical standards of the institutional and/or national research committee Curtin University Human Research Ethics Committee approval number HRE2018-0355) and with the 1964 Helsinki declaration and its later amendments or comparable ethical standards.

Informed Consent Informed consent was obtained from all individual participants included in the study.

\section{References}

Abendroth, M., \& Flannery, J. (2016). Predicting the risk of compassion fatigue: a study of hospice nurses. Journal of Hospice and Palliative Nursing, 8(6), 346-356. https://doi.org/10.1097/00129191200611000-0000.

Baer, R. A., Smith, G. T., Hopkins, J., Krietemeyer, J., \& Toney, L. (2006). Using self-report assessment methods to explore facets of mindfulness. Assessment, 13(1), 27-45. https://doi.org/10.1177/ 1073191105283504

Bishop, S. R., Lau, M., Shapiro, S., Carlson, L., Anderson, N. D., Carmody, J., Segal, Z. V., Abbey, S., Speca, M., Velting, D., \& Devins, G. (2004). Mindfulness: a proposed operational definition. Clinical Psychology: Science and Practice, 11(3), 230-241. https:// doi.org/10.1093/clipsy.bph077.

Brown, K. W., \& Ryan, R. M. (2003). The benefits of being present: mindfulness and its role in psychological well-being. Journal of Personality and Social Psychology, 84(4), 822-848. https://doi. org/10.1037/0022-3514.84.4.822.

Bürkner, P.-C. (2017). brms: an R package for Bayesian multilevel models using Stan. Journal of Statistical Software, 80(1), 1-28. https://doi.org/10.18637/jss.v080.i01.

Carre, A., Stefaniak, N., D'Ambrosio, F., Bensalah, L., \& BescheRichard, C. (2013). The Basic Empathy Scale in adults (BES-A): factor structure of a revised form. Psychological Assessment, 25(3), 679-691. https://doi.org/10.1037/a0032297.

Cass, I., Duska, L. R., Blank, S. V., Cheng, G., duPont, N. C., Frederick, P. J., Hill, E. K., Matthews, C. M., Pua, T. L., Rath, K. S., Ruskin, R., Thaker, P. H., Berchuck, A., Gostout, B. S., Kushner, D. M., \& Fowler, J. M. (2016). Stress and burnout among gynecologic oncologists: a society of gynecologic oncology evidence-based review and recommendations. Gynecologic Oncology, 143(2), 421-427. https://doi.org/10.1016/j.ygyno.2016.08.319.

Coffey, K. A., \& Hartman, M. (2008). Mechanisms of action in the inverse relationship between mindfulness and psychological distress. Journal of Evidence-Based Integrative Medicine, 13(2), 7991. https://doi.org/10.1177/1533210108316307. 
Cusack, L., Smith, M., Hegney, D., Rees, C. S., Breen, L. J., Witt, R. R., Rogers, C., Williams, A., Cross, W., \& Cheung, K. (2016). Exploring environmental factors in nursing workplaces that promote psychological resilience: constructing a unified theoretical model. Frontiers in Psychology, 7, 600. https://doi.org/10.3389/fpsyg. 2016.00600 .

Demerouti, E., Bakker, A. B., Vardakou, I., \& Kantas, A. (2003). The convergent validity of two burnout instruments: a multitraitmultimethod analysis. European Journal of Psychological Assessment, 19(1), 12-23. https://doi.org/10.1027//1015-5759.19. 1.12 .

Dobkin, P. L., \& Laliberte, V. (2014). Being a mindful clinical teacher: Can mindfulness enhance education in a clinical setting? Medical Teacher, 36(4), 347-352. https://doi.org/10.3109/0142159X.2014. 887834.

Duarte, J., \& Pinto-Gouveia, J. (2017). The role of psychological factors in oncology nurses' burnout and compassion fatigue symptoms. European Journal of Oncology Nursing, 28, 114-121. https://doi. org/10.1016/j.ejon.2017.04.002.

Figley, C. R. (1995). Compassion fatigue: coping with secondary traumatic stress disorder in those who treat the traumatized. New York: Brunner/Mazel.

Gilmartin, H., Goyal, A., Hamati, M. C., Mann, J., Saint, S., \& Chopra, V. (2017). Brief mindfulness practices for healthcare providers: a systematic literature review. American Journal of Medicine, 130(10), 1219.e1211-1219.e1217. https://doi.org/10.1016/j. amjmed.2017.05.041.

Hegney, D. G., Craigie, M., Hemsworth, D., Osseiran-Moisson, R., Aoun, S., Francis, K., \& Drury, V. (2014). Compassion satisfaction, compassion fatigue, anxiety, depression and stress in registered nurses in Australia: study 1 results. Journal of Nursing Management, 22(4), 506-518. https://doi.org/10.1111/jonm.12160.

Hunt, P. A., Denieffe, S., \& Gooney, M. (2017). Burnout and its relationship to empathy in nursing: a review of the literature. Journal of Research in Nursing, 22(1-2), 7-22. https://doi.org/10.1177/ 1744987116678902.

Jasperse, M., Herst, P., \& Dungey, G. (2014). Evaluating stress, burnout and job satisfaction in New Zealand radiation oncology departments. European Journal of Cancer Care, 23(1), 82-88. https:// doi.org/10.1111/ecc.12098.

Jensen, C. G., Niclasen, J., Vangkilde, S. A., Petersen, A., \& Hasselbalch, S. G. (2016). General inattentiveness is a long-term reliable trait independently predictive of psychological health: Danish validation studies of the Mindful Attention Awareness Scale. Psychological Assessment, 28, e70-e87. https://doi.org/10.1037/pas0000196.

Johnson, C. (1992). Coping with compassion fatigue. Nursing, 22(4), $118-120$.

Jolliffe, D., \& Farrington, D. P. (2006). Development and validation of the Basic Empathy Scale. Journal of Adolescence, 29(4), 589-611. https://doi.org/10.1016/j.adolescence.2005.08.010.

Kellner, M. E. (2001). Emergency medical professionals experiencing healthcare re-structure: Coping, empathy, and spirituality in relation to work-stress. (Doctoral dissertation) Available from ProQuest Dissertations Publishing. (UMI No. 9992969).

Klein, A., Taieb, O., Xavier, S., Baubet, T., \& Reyre, A. (2020). The benefits of mindfulness-based interventions on burnout among health professionals: a systematic review. Explore, 16, 35-43. https://doi.org/10.1016/j.explore.2019.09.002.

Krasner, M. S., Epstein, R. M., Beckman, H., Suchman, A. L., Chapman, B., Mooney, C. A., \& Quill, T. E. (2009). Association of an educational program in mindful communication with burnout, empathy, and attitudes among primary care physicians. JAMA, 302(12), 1284-1293. https://doi.org/10.1001/jama.2009.1384.

Kruschke, J. K. (2015). Doing Bayesian data analysis: a tutorial with $R$, $J A G S$, and Stan (2nd ed.). Elsevier.
Litten, V., Roberts, L. D., Ladyshewsky, R. K., Castell, E., \& Kane, R. (2018). The influence of academic discipline on empathy and psychopathic personality traits in undergraduate students. Personality and Individual Differences, 123, 145-150. https://doi.org/10.1016/j. paid.2017.11.025.

Maslach, C., \& Jackson, S. E. (1981). The measurement of experienced burnout. Journal of Occupational Behavior, 2(2), 99-113. https:// doi.org/10.1002/job.4030020205.

McElreath, R. (2018). Statistical rethinking: a Bayesian course with examples in R and Stan. Boca Raton: CRC Press.

Mills, J., Wand, T., \& Fraser, J. A. (2018). Exploring the meaning and practice of self-care among palliative care nurses and doctors: a qualitative study. BMC Palliative Care, 17(1). https://doi.org/10. 1186/s12904-018-0318-0.

Najjar, N., Davis, L. W., Beck-Coon, K., \& Carney Doebbeling, C. (2009). Compassion fatigue: a review of the research to date and relevance to cancer-care providers. Journal of Health Psychology, 14(2), 267-277. https://doi.org/10.1177/1359105308100211.

Osman, A., Lamis, D. A., Bagge, C. L., Freedenthal, S., \& Barnes, S. M. (2015). The Mindful Attention Awareness Scale: further examination of dimensionality, reliability, and concurrent validity estimates. Journal of Personality Assessment, 98(2), 189-199. https://doi.org/ 10.1080/00223891.2015.1095761.

Perron, B., \& Hiltz, B. (2006). Burnout and secondary trauma among forensic interviewers of abused children. Child and Adolescent Social Work Journal, 23, 216-234. https://doi.org/10.1007/ s10560-005-0044-3.

Peterson, U., Demerouti, E., Bergström, G., Asberg, M., \& Nygren, Å. (2008). Work characteristics and sickness absence in burnout and nonburnout groups: a study of Swedish health care workers. International Journal of Stress Management, 15(2), 153-172. https://doi.org/10.1037/1072-5245.15.2.153.

Podsakoff, P. M., MacKenzie, S. B., Lee, J. Y., \& Podsakoff, N. P. (2003). Common method biases in behavioral research: a critical review of the literature and recommended remedies. Journal of Applied Psychology, 88(5), 879-903. https://doi.org/10.1037/ 0021-9010.88.5.879.

R Core Team. (2020). R: a language and environment for statistical computing. Vienna: R Foundation for Statistical Computing https://www.R-project.org/.

Rees, C., Craigie, M., Slatyer, S., Heritage, B., Harvey, C., Brough, P., \& Hegney, D. (2018). Mindful self-care and resiliency (MSCR): protocol for a pilot trial of a brief mindfulness intervention to promote occupational resilience in rural general practitioners. BMJ Open, 8(6), e021027. https://doi.org/10.1136/bmjopen-2017-021027.

Revelle, W., \& Condon, D. M. (2019). Reliability from $\alpha$ to $\omega$ : a tutorial. Psychological Assessment, 31(12), 1395-1411. https://doi.org/10. 1037/pas0000754.

Samios, C. (2017). Burnout and psychological adjustment in mental health workers in rural Australia: the roles of mindfulness and compassion satisfaction. Mindfulness, 9(4), 1088-1099. https://doi.org/ 10.1007/s12671-017-0844-5.

Scanlan, J. N., \& Still, M. (2019). Relationships between burnout, turnover intention, job satisfaction, job demands and job resources for mental health personnel in an Australian mental health service. $B M C$ Health Services Research, 19, 62. https://doi.org/10.1186/s12913018-3841-z.

Schaufeli, W. B., Leiter, M. P., Maslach, C., \& Jackson, S. E. (1996). The MBI-general survey. In C. Maslach, S. E. Jackson, \& M. P. Leiter (Eds.), Maslach Burnout Inventory manual (3rd ed.). Consulting Psychologists Press.

Schaufeli, W. B., Bakker, A. B., Hoogduin, K., Schaap, C., \& Kladler, A. (2001). On the clinical validity of the Maslach Burnout Inventory and the Burnout Measure. Psychology and Health, 16, 565-582. https://doi.org/10.1080/08870440108405527. 
Schaufeli, W. B., Leiter, M. P., \& Maslach, C. (2009). Burnout: 35 years of research and practice. Career Development International, 14(3), 204-220. https://doi.org/10.1108/13620430910966406.

Shoji, K., Lesnierowska, M., Smoktunowicz, E., Bock, J., Luszczynska, A., Benight, C. C., \& Cieslak, R. (2015). What comes first, job burnout or secondary traumatic stress? Findings from two longitudinal studies from the U.S. and Poland. PLoS ONE, 10(8), e0136730. https://doi.org/10.1371/journal.pone.0136730.

Silver, J., Caleshu, C., Casson-Parkin, S., \& Ormond, K. (2018). Mindfulness among genetic counselors is associated with increased empathy and work engagement and decreased burnout and compassion fatigue. Journal of Genetic Counseling, 27(5), 1175-1186. https://doi.org/10.1007/s10897-018-0236-6.

Slatyer, S., Craigie, M., Heritage, B., Davis, S., \& Rees, C. (2017). Evaluating the effectiveness of a brief mindful self-care and resiliency (MSCR) intervention for nurses: a controlled trial. Mindfulness, 9(2), 534-546. https://doi.org/10.1007/s12671-0170795-x.

Stamm, B. H. (2010). The concise ProQOL manual (2nd ed). https:// proqol.org/uploads/ProQOLManual.pdf.

Taylor, N. Z., \& Millear, P. M. R. (2016). The contribution of mindfulness to predicting burnout in the workplace. Personality and Individual Differences, 89, 123-128. https://doi.org/10.1016/j.paid. 2015.10.005.

Trufelli, D. C., Bensi, C. G., Garcia, J. B., Narahara, J. L., Abrao, M. N., Diniz, R. W., Da Costa Miranda, V., Soares, H. P., \& Del Giglio, A. (2008). Burnout in cancer professionals: a systematic review and meta-analysis. European Journal of Cancer Care, 17(6), 524-531. https://doi.org/10.1111/j.1365-2354.2008.00927.x.

Turnell, A., Rasmussen, V., Butow, P., Juraskova, I., Kirsten, L., Wiener, L., Patenaude, A., Hoekstra-Weebers, J., \& Grassi, L. (2016). An exploration of the prevalence and predictors of work-related wellbeing among psychosocial oncology professionals: an application of the job demands-resources model. Palliative and Supportive Care, 14(1), 33-41. https://doi.org/10.1017/S1478951515000693.

Van Dam, N. T., Earleywine, M., \& Borders, A. (2010). Measuring mindfulness? An item response theory analysis of the Mindful Attention Awareness Scale. Personality and Individual Differences, 49(7), 805-810. https://doi.org/10.1016/j.paid.2010. 07.020 .

van Mol, M. M., Kompanje, E. J., Benoit, D. D., Bakker, J., \& Nijkamp, M. D. (2015). The prevalence of compassion fatigue and burnout among healthcare professionals in intensive care units: a systematic review. PLoS One, 10(8), e0136955. https://doi.org/10.1371/ journal.pone.0136955.

Wagaman, M. A., Geiger, J. M., Shockley, C., \& Segal, E. A. (2015). The role of empathy in burnout, compassion satisfaction, and secondary traumatic stress among social workers. Social Work, 60(3), 201209. https://doi.org/10.1093/sw/swv014.

Wilkinson, H., Whittington, R., Perry, L., \& Eames, C. (2017). Examining the relationship between burnout and empathy in healthcare professionals: a systematic review. Burnout Research, 6, 18-29. https://doi.org/10.1016/j.burn.2017.06.003.

Xu, W., An, Y., Ding, X., Yuan, G., Zhuang, Y., \& Goh, P. (2017). Dispositional mindfulness, negative posttraumatic beliefs, and academic burnout among adolescents following the 2016 Yancheng tornado. Personality and Individual Differences, 116, 405-409. https://doi.org/10.1016/j.paid.2017.05.029.

Yates, M., \& Samuel, V. (2019). Burnout in oncologists and associated factors: a systematic literature review and meta-analysis. European Journal of Cancer Care, 28(3), e13094. https://doi.org/10.1111/ecc. 13094.

Publisher's Note Springer Nature remains neutral with regard to jurisdictional claims in published maps and institutional affiliations. 